\title{
Controller design for PV experimental bench with ADRC strategy supervised by Labview created interface
}

\author{
Naoufel Khaldi' ${ }^{1}$, Youssef Barradi ${ }^{2}$, Khalida Zazi ${ }^{3}$, Malika Zazi ${ }^{4}$ \\ ${ }^{1}$ Energy and Sustainable Development Research Team, High School of Technology, Ibn Zohr University, Guelmim, \\ Morocco \\ ${ }^{2,3,4}$ Electrical Engineering Department in National School of Arts and Crafts (ENSAM), Mohammed V University, Rabat, \\ Morocco
}

\begin{tabular}{|c|c|}
\hline Article Info & ABSTRACT \\
\hline Article history: & The converter control scheme plays an important role in the performance of \\
\hline Received Feb 20, 2021 & $\begin{array}{l}\text { maximum power point tracking (MPPT) algorithms. In this work, a model } \\
\text { has been analysed, designed and simulatedon Power Simulator software and }\end{array}$ \\
\hline Revised Apr 3, 2021 & in Matlab Simulink.A hardware implementation using a microcontroller \\
\hline Accepted Apr 15, 2021 & $\begin{array}{l}\text { (Arduino Mega } 2560 \text { based on ATmega2560) is provided, that operateson } \\
\text { feedback from a PV panel voltage and current to control the operation of DC- }\end{array}$ \\
\hline Keywords: & $\begin{array}{l}\text { DC converter in order to draw maximum power. Newactive disturbance } \\
\text { rejection control (ADRC) algorithm is required to extract the maximum }\end{array}$ \\
\hline ADRC strategy & power of the solar energy. This MPPT controller incorporates a boost \\
\hline Arduino board & $\begin{array}{l}\text { topology that ensuresa two continuous battery in series }(12 \mathrm{~V}, 5 \mathrm{Ah}) \text { charging } \\
\text { in various conditions. The whole of the results shows in one hand that the }\end{array}$ \\
\hline Boost converter & converter efficiency is very satisfactory, and in the other hand a very good \\
\hline Labview & agreement between the results simulated and those experimental in terms of \\
\hline MPPT & $\begin{array}{l}\text { performance. The proposed system is designed in Proteus, and implemented } \\
\text { on hardware with a graphical user interface built throughout Labview } \\
\text { software. }\end{array}$ \\
\hline
\end{tabular}

This is an open access article under the CC BY-SA license.

\section{Corresponding Author:}

Khaldi Naoufel

Energy and Sustainable Development Research Team

High School of Technology

Ibn Zohr University, 81000, Guelmim, Morocco

Email:n.khaldi@uiz.ac.ma

\section{INTRODUCTION}

In Demand for electrical energy has remarkably increased during the recent years with growing population and industrial progress [1]. Since long time ago, fossil fuels have served as the major source of generating electrical energy. However Solar PV based applications are generally most pertinent to distributed generation in locations where the grid is unavailable or unreliable, also the global installed capacity for solar PV is incresead especially by China, India and United States [2]. However, the key to the success of applying small PV energy systems is a simple, low cost and high-performance converter. So, a boost converter is designed that it provides an output of $24 \mathrm{~V}$ DC, which is the battery input. The transfer of energy resulting from photovoltaic conversion remains relatively weak. Therefore, many tracking control strategies have been proposed in existing literatures, such as perturb and observe [3], fuzzy logic [4], parasite capacitance, and other methods [5]-[6]. Some of them are even implemented. In this paper, the role of MPPT strategy is to attain the MPP of the PV panel even with variation of the atmospheric conditions. The designed system controls the duty cycle of the converter and ensure the opening and the closing of the Mosfet using a 
designed driver which deliver a high pulse with modulation (PWM) frequency [7]. The current and the voltage needed as inputs for the controller are obtained through a designed current and voltage sensors.

The system was designed by Proteus, simulated by Pspice simulator and Matlab Simulink using a new ADRC strategy to extract the maximum power from the PV panel [8]-[9]. The proposed method is a new technology for estimating and compensating uncertainties and disturbances, which have been explored and used recently as an alternative over classical techniques and especially PID controller [10]-[11]. Unlike many existing control methods, the ADRC does not require the accurate mathematical model of the plant. Moreover, selecting the plant order $\mathrm{n}$ of the ADRC is quite flexible which make this control more convenient to apply in many control systems [10]-[12]. The method involves three blocks: differentiator trackers (DT), feedback controller (FC), and extended state observer (ESO) which is the main part of the command [12][13]. An implementation is ensured under an electronic platform board (Arduino Mega) with a novel control application developed in Labview environment which provided a real time operation and supervision, a practical user interface, and more other abilities. Results shows good performance, high accuracy and robustness comparing simulation and implementation.

The sequential work flow of this paper is as follows: In section 2, complete working procedure of the system has been described. Section 3 covers the design of boost DC-DC converter, followed by the design of current sensor, voltage sensor, after that the driver and a discussion about a MPPT command, in Section 4. Simulation results and experimental works are discussed in Section 5 and 6 respectively. Lastly, in section 7 , a precise conclusion has been added to finalize the work.

\section{COMPLETE SYSTEM OVERVIEW}

A photovoltaic cell is basically a PN semiconductor junction diode which is converting sun energy into electrical energy [14]. DC-DC converter is widely used as an intermediary between the PV and load or battery. Solar panel's current and voltage are fed to the microcontroller which deliver a suitable duty cycle to the boost converter on the basis of an algorithm. The whole system is given in Figure 1.

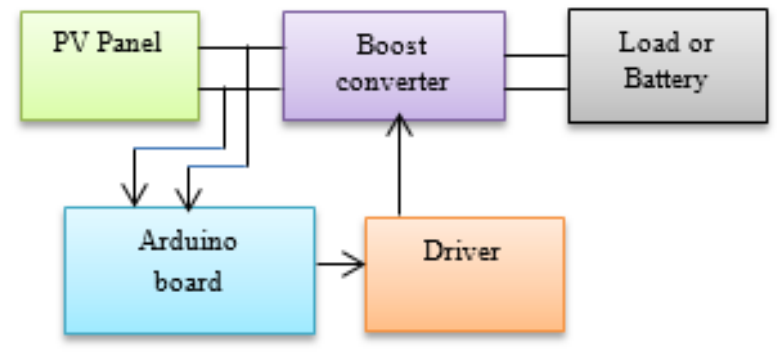

Figure 1. PV System adapted by Boost converter

\subsection{Solar panels characteristics}

Parameters of solar panel are shown in Table 1. PV module is made by solar company and product name is MLP-020P. Numerical method called Newton-Raphson is used to determine the operational point [14]. The system is described by (1)-(3) below, meaning of the parameters expressed can be consulted in [6], [14].

Table 1. Parameters of mlp-020P

\begin{tabular}{cl}
\hline Parameters & \multicolumn{1}{c}{ Values } \\
\hline Open Circuit Voltage (Voc) & 21.7 Volt \\
Short Circuit Current (Isc) & $1.26 \mathrm{Amp}$ \\
Voltage at Pmax (Vmpp) & 17.3 Volt \\
Current at Pmax (Impp) & $1.17 \mathrm{Amp}$ \\
Maximum Power (Pmpp) & 20Watt \\
\hline
\end{tabular}

$$
i_{p v}=n_{p} I_{p h}-n_{p} I_{r s}\left[\exp \left(\frac{q}{p k n_{s}} \times \frac{v_{p v}}{T}\right)-1\right]
$$




$$
\begin{aligned}
& I_{r s}=I_{r}\left(T / T_{r e f}\right)^{3} \exp ^{\left\{\left(\frac{q E g}{p k}\right)\left(\frac{1}{T}-\frac{1}{T_{r e f}}\right)\right\}} \\
& I_{p h}=\left[\left(I_{s c}+K\left(T-T_{r}\right)\right] \times\left(\frac{E}{E_{r}}\right)\right.
\end{aligned}
$$
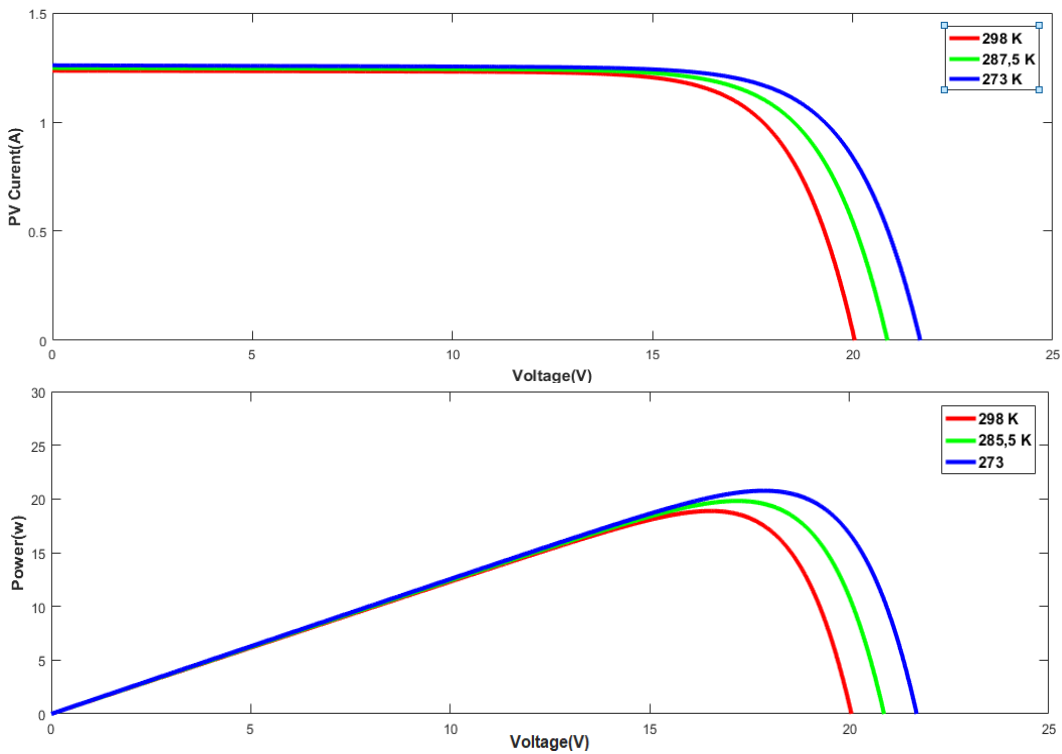

Figure 2. Temperature variation effect in PV
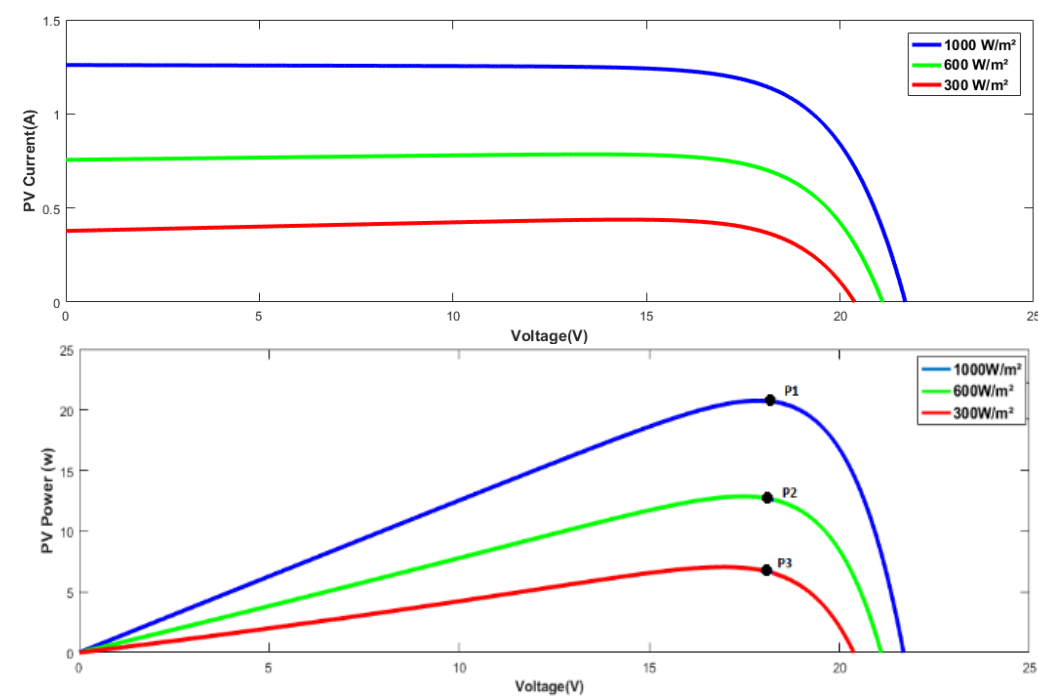

Figure 3. Irradiation variation effect in PV

\section{DC-DC BOOST CONVERTER}

DC-DC converters can be used as switching mode regulators to convert an unregulated DC voltage to a regulated DC output voltage [14]-[15]. The regulation is normally achieved by PWM and the controlled switch is normally MOSFET or IGBT [16].

Figure 4 below shows a step up or boost converter. It consists of a PV voltage $V_{p v}$ as input; boost inductor $\mathrm{L}$, input capacitor $C_{i n}$, transistor Mosfet, Diode $\mathrm{D}$, output capacitor $C_{o}$, and a Load or battery. Maximum power is reached when the MPPT algorithm changes and adjusts the duty cycle of the switched device [17]. 


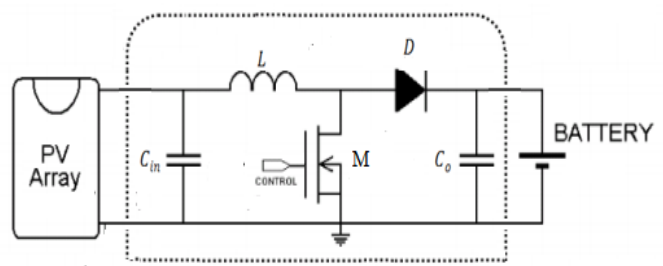

Figure 4. Boost DC-DC converter with PV as input

\subsection{Duty cycle}

The relation between input and output voltage included a factor of efficiency which contribute to calculate a more reasonable duty cycle d:

$$
\mathrm{V}_{\text {out }}=\frac{\eta}{1-\mathrm{d}} \mathrm{V}_{\text {in }}
$$

where $\eta$ called efficiency of the converter, is about $80 \%$, then $d=0.43$.

\subsection{Inductor Selection}

The given parameters are required to calculate the power stage (inductance and capacitance). We have input voltage $V_{p v}=17 \mathrm{~V}$, desired output voltage $V_{b a t}=25 \mathrm{~V}$ (slightly higher than the rated voltage of the two batteries series which is $24 \mathrm{~V}$ ), and the output current $\mathrm{I}_{\text {out }}=1 \mathrm{~A}$.

In order to calculate the estimated inductance value $\mathrm{L}$ of converter, we need to calculate first the estimated current ripple $\Delta \mathrm{I}_{L}$ :

$$
\Delta \mathrm{I}_{L}=0.3 \times \mathrm{I}_{\text {out }} \times \frac{V_{\text {bat }}}{V}
$$

$\Delta \mathrm{I}_{L}=0.45 \mathrm{~A}$

A smaller ripple reduces the magnetic hysteresis losses in the inductor component. The switching frequency for this project is taken to be $\mathrm{f}=62.5 \mathrm{Khz}$.

The inductor value $\mathrm{L}$, according to varied parameters, is given below:

$L=\frac{V_{p v}}{\mathrm{f} . \Delta \mathrm{I}_{L}} \cdot d$

We take $\mathrm{L}=200 \mu H$.

\subsection{Input capacitor Selection}

The equation of the input capacitor is given as:

$$
C_{\text {in }}=\frac{V_{p v}}{L \cdot \mathrm{f}^{2} \cdot \Delta \mathrm{V}_{p v}} \cdot D
$$

We take $C_{i n}=100 \mu F$ with $\Delta \mathrm{V}_{p v}$ an input voltage ripple $\Delta \mathrm{V}_{p v}<100 \mathrm{mV}$.

If the input ripple is high then it will require a large value of capacitance, and that result an increase in losses caused by the ESR.

\subsection{Output capacitor Selection}

The output capacitor is:

$$
C_{\text {out }}=\frac{I_{\text {Out }}}{\mathrm{f} . \Delta \mathrm{V}_{\text {out }}} \cdot D
$$

we take $C_{\text {out }}=800 \mu \mathrm{F}$. Where $\Delta \mathrm{V}_{\text {out }}<10 \mathrm{mV}$ is the output ripple voltage, a large value can cause a fluctuation up to the limits where the output voltage crosses the limits of battery ratings. 


\section{ADRC CONTROLLER DESIGN}

\subsection{ADRC Algorithm}

To improve the response speed and control adaptability of the power system [18], the applied ADRC method design is shown in Figure 6. The main idea of this technology is to estimate and compensate the unmeasured state of the system or the total disturbance, in real time, even without an explicit model of the plant and only from the input-output information [19]-[20]. To ensure that, the controller contains three blocks: differentiator trackers (DT), feedback controller (FC), and extended state observer (ESO). It involves also an inner loop to reject the total disturbance and an outer one to deliver the desired signal [21]-[22]. This proposed algorithm is implemented in an Arduino board to control the duty cycle of the DC-DC converter in order to track the MPP even with climatic variations.

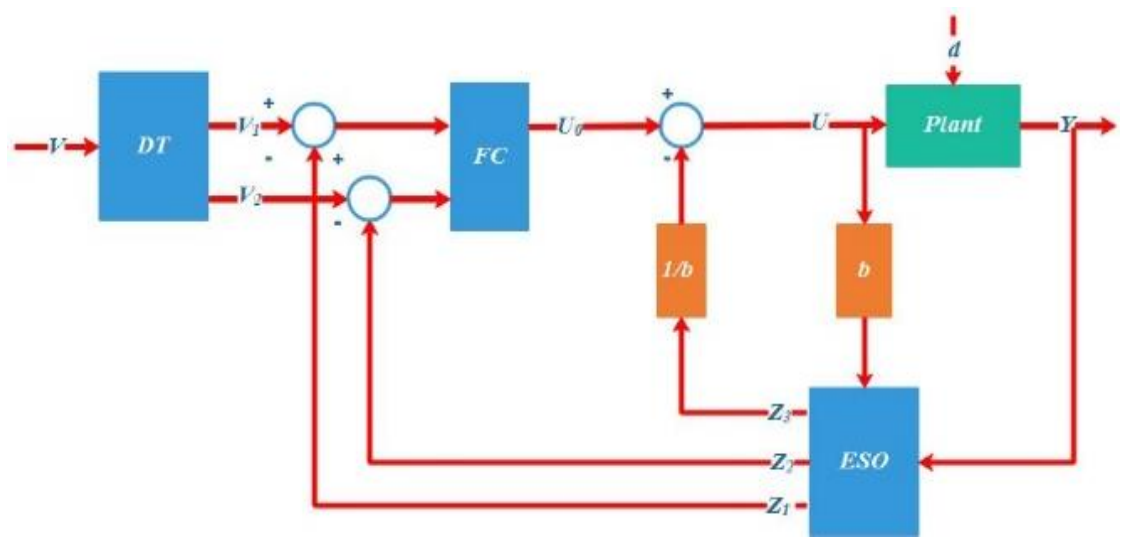

Figure 5. ADRC controller structure

As shown in Figure 6, to extract the maximum power from the PV System, the ADRC controller is designed to set the following signal error at 0 .

$$
e=\frac{I}{V}+\frac{d I}{d V}
$$

DT is used to arrange the transient process, and to get the differential signals of current dI and voltage dV with two differentiators' trackers.

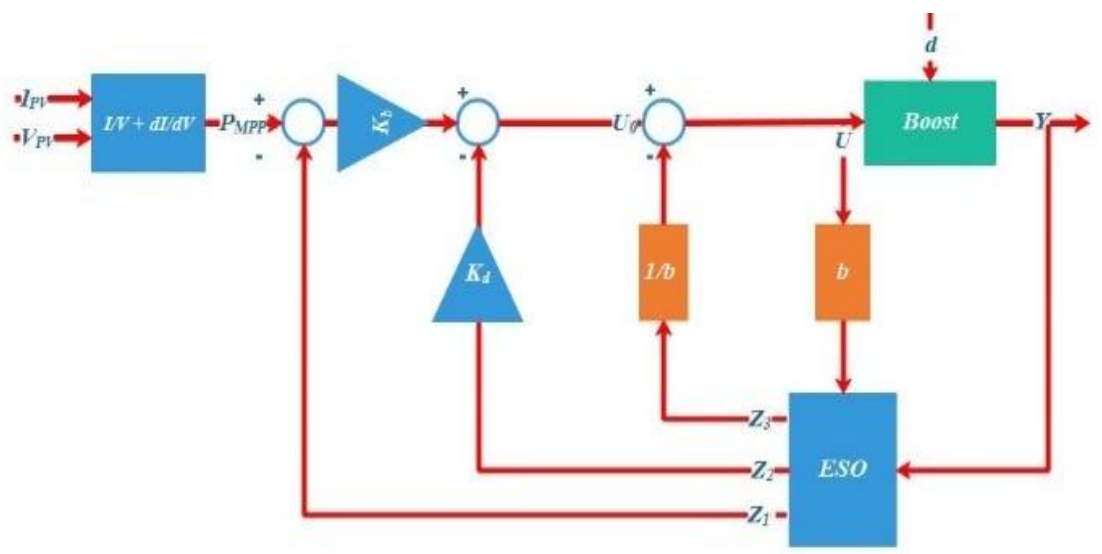

Figure 6. MPPT based in ADRC controller

It overcomes the drawback in the classical theory such as an amplificatory effect on the noise. Mathematical form is expressed by: 


$$
\left\{\begin{array}{c}
\dot{X}_{1}=X_{2} \\
\dot{X}_{2}=m \psi\left(X_{1}-X+\frac{X_{2}\left|X_{2}\right|}{2 m}\right)
\end{array}\right.
$$

Where $\mathrm{m}$ is the speed factor, $X_{1}$ and $X_{2}$ are respectively the tracking and differential output, $\mathrm{X}$ is the input signal and $\psi($.$) is a nonlinear function.$

ESO is the core part of ADRC, it contributes to get the model uncertainty and to deal with total disturbance affecting PV Power system. Mathematical structure is given by:

$$
\left\{\begin{array}{c}
e=z_{1}-y \\
\dot{z}_{1}=z_{2}-\theta_{1} e \\
\dot{z}_{2}=z_{3}-\theta_{2} e \\
\dot{z}_{3}=-\theta_{3} e
\end{array}\right.
$$

where $y$ is the output of the system. $z_{1}, z_{2}$ and $z_{3}$ are respectively the estimation of the output, the estimation of the derivative of the output and the estimation of the disturbance in system. Referring to [23], the observer gains $\theta_{i}(i=1,2,3)$ are $3 \omega_{0}, 3 \omega_{0}{ }^{2}, \omega_{0}{ }^{3} . K_{P}=\omega_{c}{ }^{2}, K_{d}=2 \omega_{c}$ parameters of the feedback controller (FC) are used to generate the control input $u_{0}$.

$\omega_{0}$ is denoted as the bandwidth of the observer and $\omega_{c}$ the bandwidth of the feedback control. Finally, the control law is:

$$
u=\frac{u_{0}-z_{3}}{b}
$$

$\mathrm{b}$ is the disturbance compensation factor

\subsection{Inputs sensors}

The PV panel output is followed by a circuitry for sensing the current and voltage needed as inputs for the MPPT algorithm as shown in Figure 7. A voltage divider which converts the voltage of PV panel in range that is $0-5 \mathrm{~V}$, so that the Arduino board can interpret the voltage level. The combination of resistor in voltage divider is high almost $10 \mathrm{~K} \Omega$ in order to minimize the power losses.

Direct current sensing is based on Ohm's law. A current sensing module named as ACS712 can be used [24], but we designed our proper sensor by placing a high shunt resistor $R_{1}$ in series with the system load, a voltage is generated across the shunt resistor that is proportional to the system load current. The voltage across the shunt can be measured by differential amplifier LM324 and deliver a readable current value to the Arduino board.

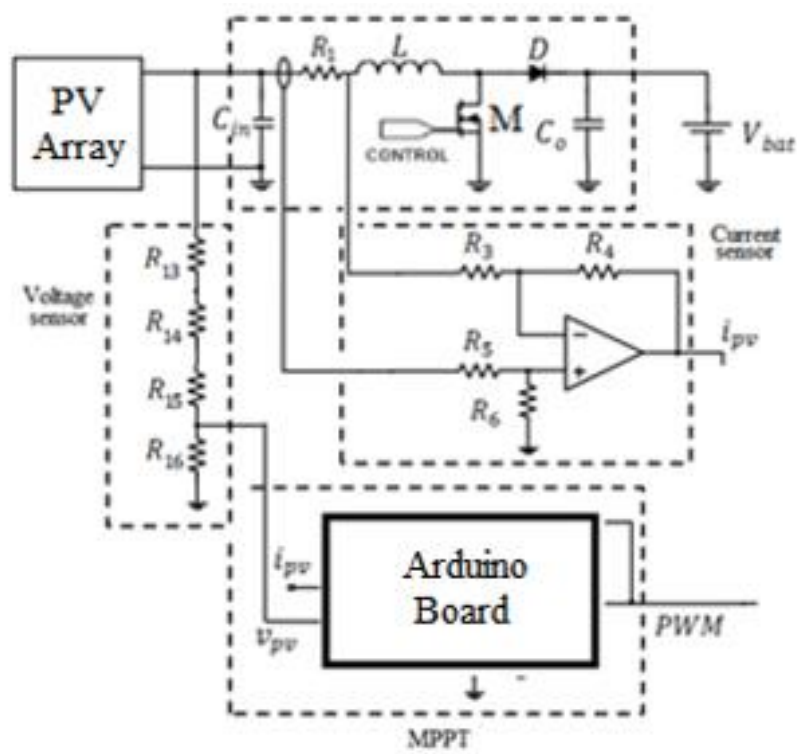

Figure 7. current and voltage sensors 
Figure 8 shows the driver designed to transmit the signal PWM to MOSFET transistor of the boost converter. It has capability of operating at high PWM frequency $62.5 \mathrm{KHz}$ that the boost converter gets, with a specific duty cycle for its MOSFET, from the Arduino board. There is a level shifting circuitry using a push-pullamplifier as an output stage between Arduino board and converter. It increases the level of PWM from Arduino board according to the gate to source voltage of MOSFET (from 5V to12V).

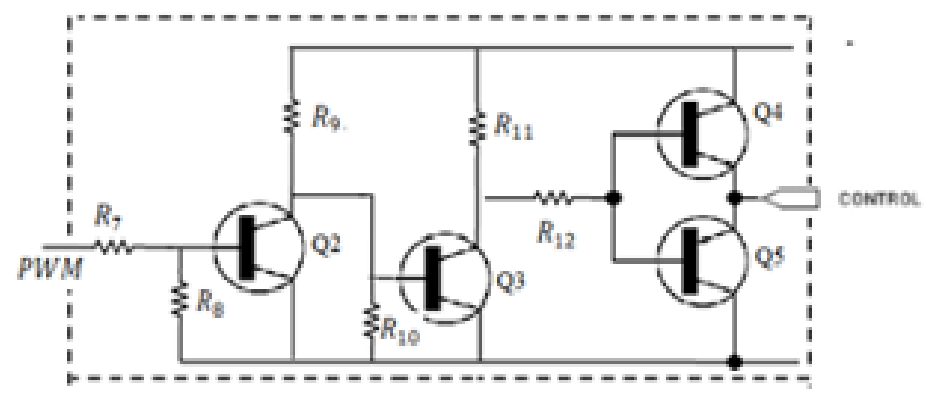

Figure 8. Driver for boost converter

\section{SIMULATION AND RESULTS}

In order to investigate the performance of our system, we have implemented the complete circuit, as shown by Figure 4, in first time in Pspice simulator environment and then in MATLAB/Simulink using for both simulation an ADRC algorithm.

In the first simulation, the PV panel and the MPPT algorithm were modeled respectively by a solar panel bloc and microcontroller bloc. The PV panel is connected to a resistive load through a boost converter whose duty cycle was adjusted by MPPT algorithm based on the value of current and voltage sensors (Fig 9).

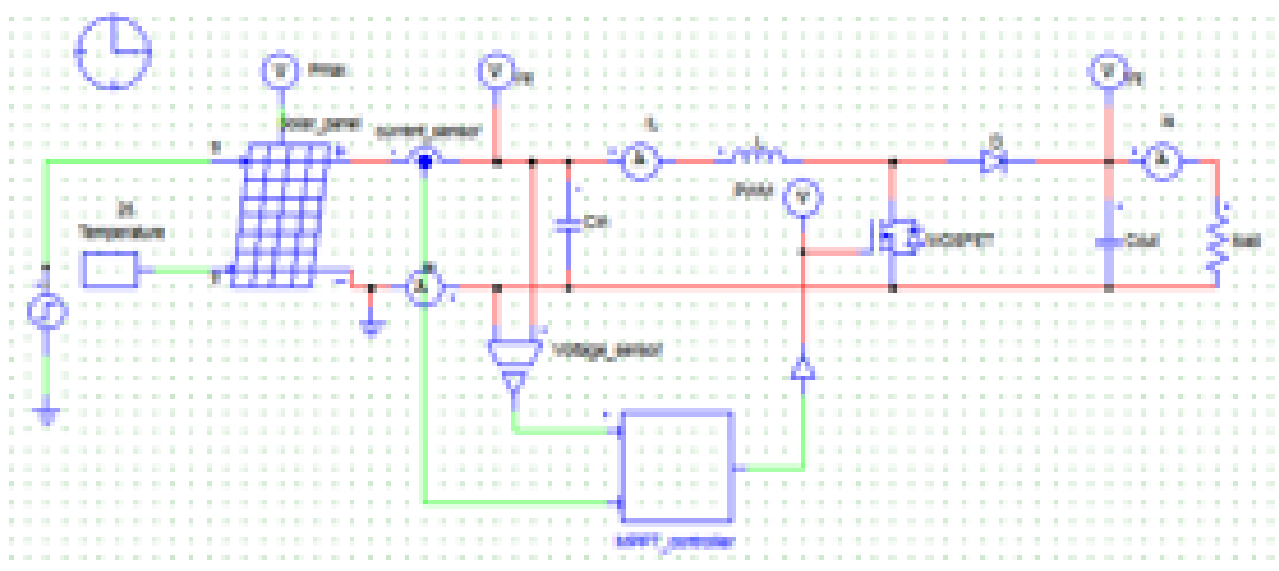

Figure 9. The whole system

In Figure 10, the output power curve by using MPPT algorithm which produce a suitable duty cycle used to reach the MPP, has an excellent characteristic with high accuracy and good stability. The results concerning the input (output) voltage and input (output) current of the converter was presented respectively in Figure 11 and 12. They show that the electric quantitie soscillate around the optimal values under the optimal conditions.

Finally, Figure 13 shows that the MPPT algorithm can quickly track the MPP $(t=10 \mathrm{~ms})$ with good efficiency and low oscillation even with the variation of irradiation. 


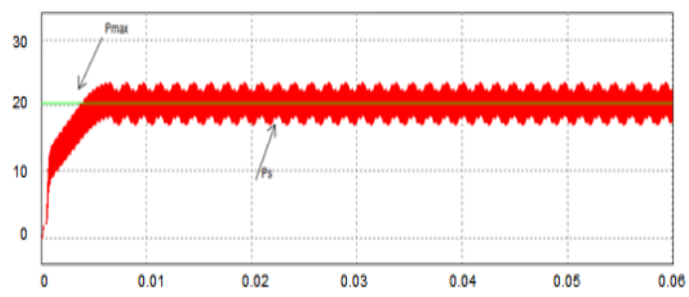

Figure 10. Output Power with MPPT algorithm

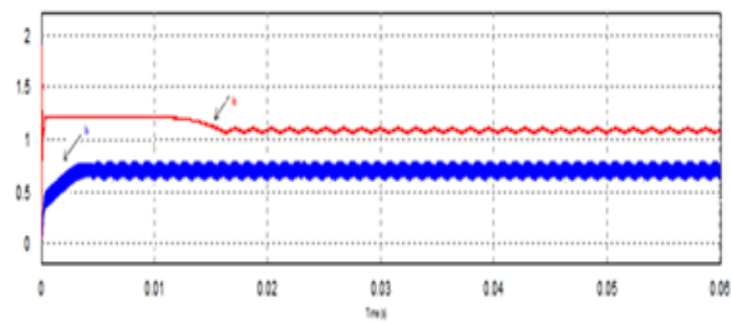

Figure 12. Input \& Output Current of the converter

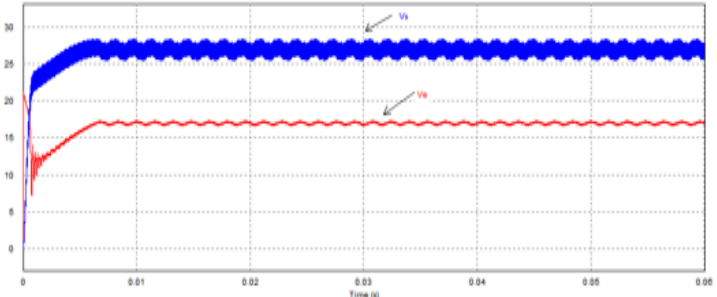

Figure 11. Input \& Output voltage of the converter

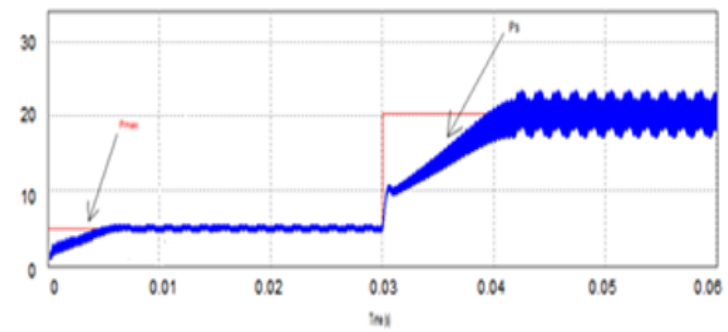

Figure 13. Output Power with variation of irradiation

In the second simulation, the power system was carried out in MATLAB Simulink as shown in Figure 13. Parameters used in ADRC algorithm for the boost converter are $\omega_{0}=440, \omega_{0}=110$ and $b=600$. Performances and design results of the control system are illustrated throughout two cases. In the first scenario, realistic ramp up/down radiation from $1000 \mathrm{w} / \mathrm{m}^{2}$ to $300 \mathrm{w} / \mathrm{m}^{2}$ are applied while the temperature is kept constant at $298 \mathrm{~K}$. In the second case, the temperature changes its values as follows: $323 \mathrm{~K}$ to $298 \mathrm{~K}$ at $t=1.2 \mathrm{~s}$ and from $298 \mathrm{~K}$ returning to $323 \mathrm{~K}$ at $1.8 \mathrm{~s}$ meanwhile the radiation is maintained at $1000 \mathrm{w} / \mathrm{m}^{2}$.

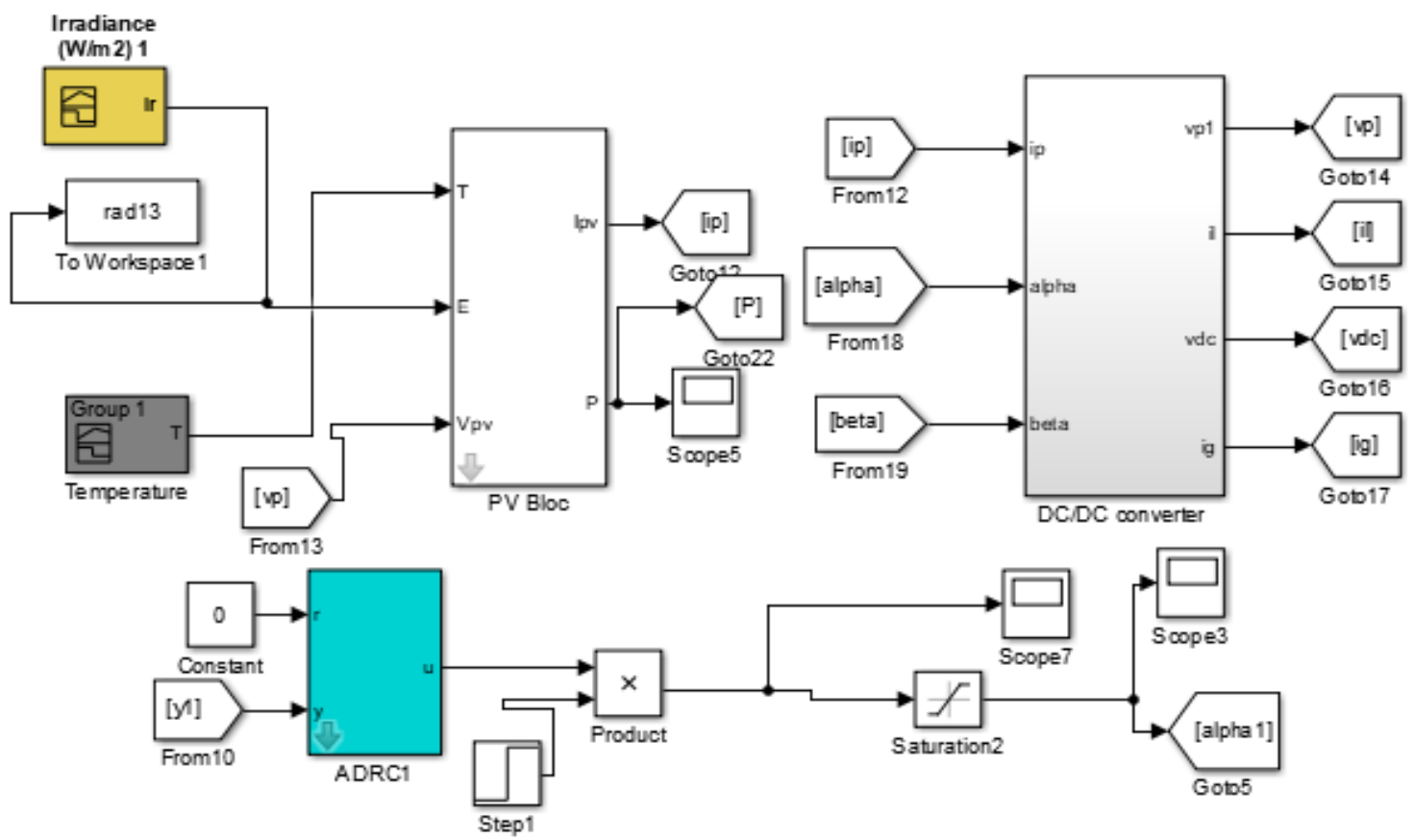

Figure 14. Power system simulation 
The resulting control performances of the first case is illustrated by Figure 14 to Figure 17 and for the second one is illustrated by Figure 18 to Figure 21. Figures 14 and 18 shows that the ADRC technique deliver a control signal which drive the boost converter to track the MPP very quickly. As illustrated in Figure 14, the PV output power is 20w, 6w, corresponding to the MPP P1 and P3 in Figure 3. Moreover, noting that the output voltage is regulated to its desired value $25 v$ with good performance. Finally, the control inputs of converter dis clearly bounded. Sequentially all these figures coincide with theoretical prediction and company specified value which ensures the validity of the system.

According to figures, the ADRC command present excellent characteristics and good performances even withsomeremarkable oscillation and high overshoot at the first $500 \mathrm{~ms}$, which due to the time taken by the approach to transform the data of the problem using Simulink into a set of results. Otherwise, for an implementation, ADRC method is generally cheaper and less complex because it requires only two tuning parameters to adjust.

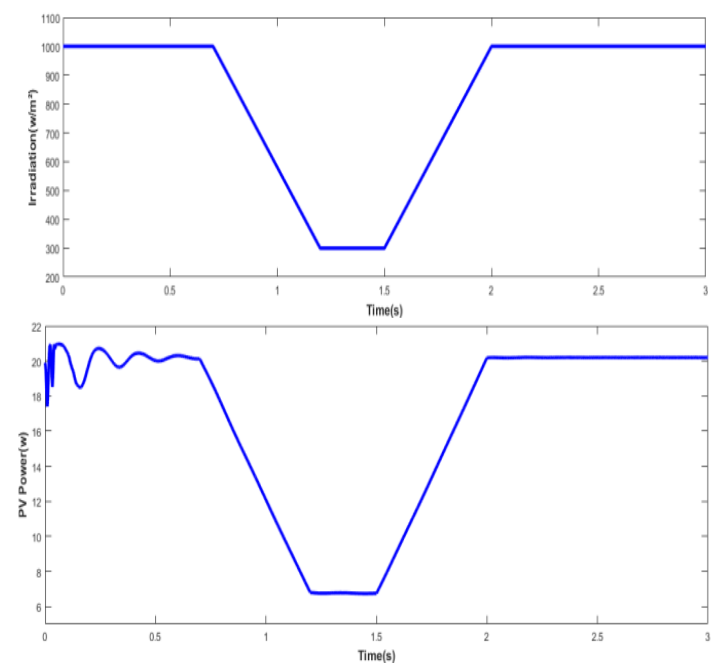

Figure 14. Output Power with irradiation change
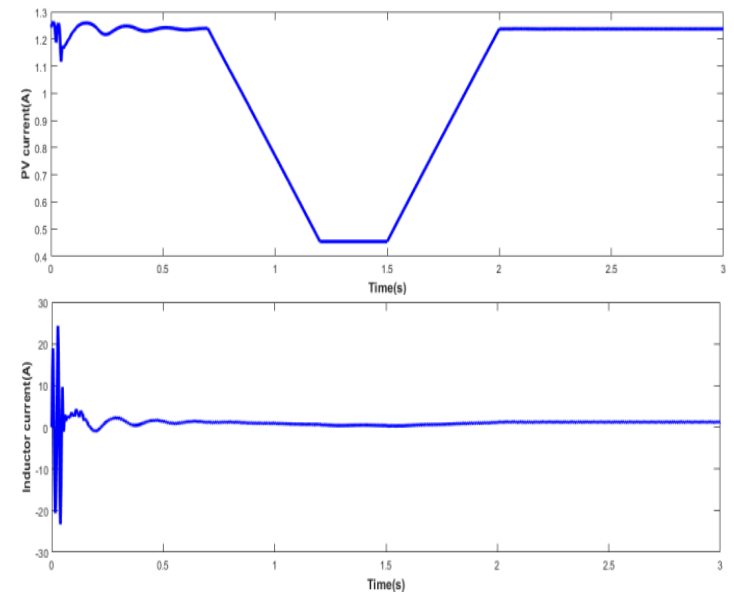

Figure 16. Input \& inductor current of the converter

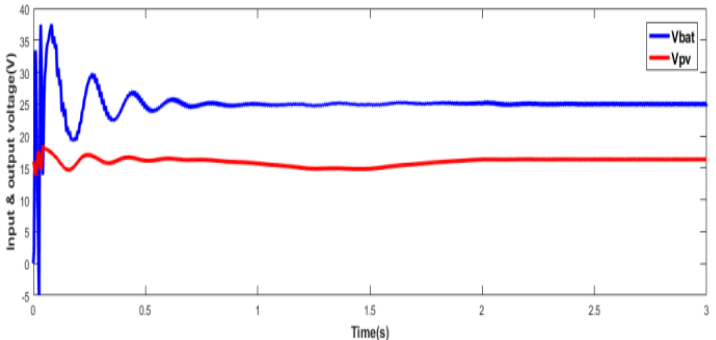

Figure 15. Input \& output voltage converter

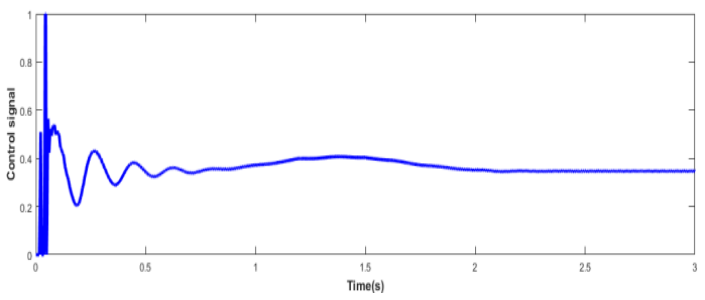

Figure 17. Duty cycle of the converter 


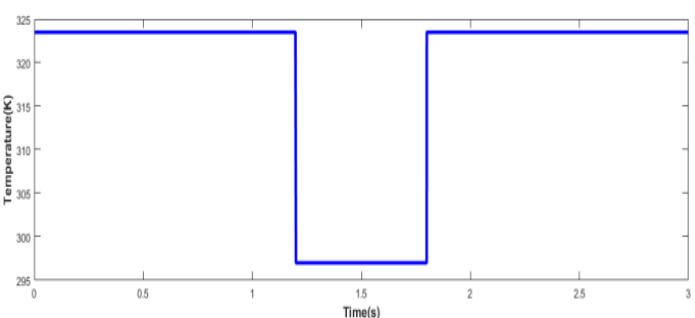

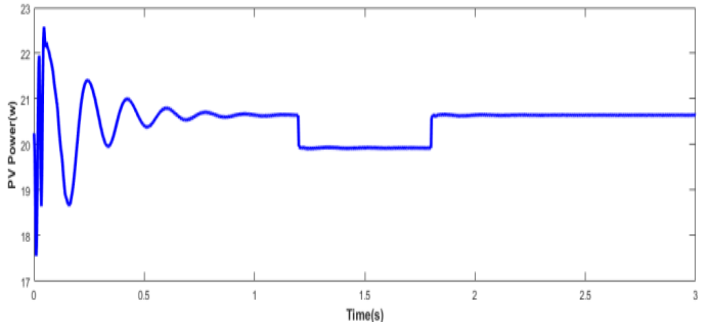

Figure 18. Output Power with temperature change
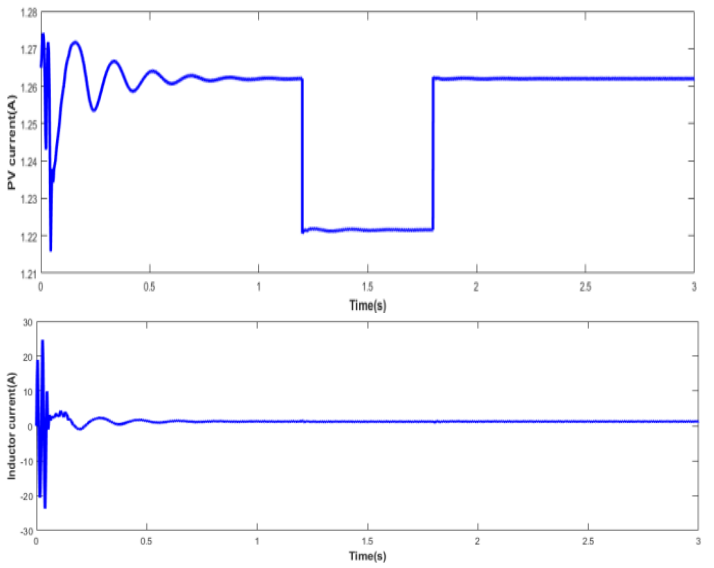

Figure 20. Input \& inductor current of the converter

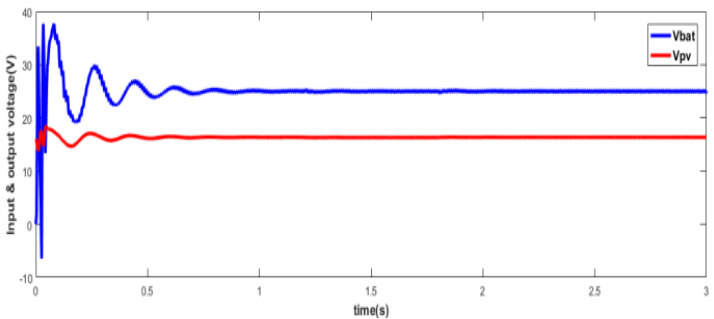

Figure 19. Input \& output voltage converter

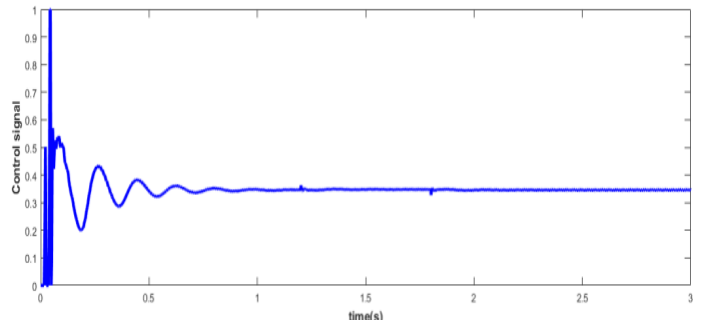

Figure 21. Duty cycle of the converter

\section{EXPERIMENTAL WORK}

The MPPT algorithm was been implemented by using an Arduino board and Labview application which are designed in such way that can perform with any other research MPPT algorithm. For our MPPT algorithm, the analog signals $v_{p v}$ and $i_{p v}$ obtained by the designed sensors is a means of two pins A0 and A1 of the Arduino device.

\subsection{System design and simulation on ISIS}

Figure 22 presents the design of the whole system on ISIS Proteus. In view of a minimization of losses, the boost converter is designed around a Mosfet IRFP250 which present a small $R_{d s}($ on $)=0.085 \Omega$, and around a low voltage diode such as Schottky diode whose well adapted for this application due to its low voltage drop and short switching time. divider:

A voltage and current sensors are needed. The first one to detect voltage of the PV panel by using a

$$
V_{\text {out }}=\frac{R_{16}}{R_{16}+R_{9}+R_{5}+R_{15}} v_{p v}
$$

which must be $<5 \mathrm{~V}$ because the analog input in Arduino is limited to $5 \mathrm{~V}$. The second one to measure the output panel current and they transmitted to the analog pin A1. 
Two Zener diodes (1N4733A) and two capacitors $C_{3}, C_{4}$ mounted on the sensors, are used to protect the Arduino board and charge controller against abnormal and extreme operating conditions such us over voltage or overload.

The driver increases the amplitude of its input PWM signal (pin5) in order to deliver a suitable duty cycle to gate to source voltage $V_{G S}$ (from $5 \mathrm{~V}$ to $12 \mathrm{~V}$ ) to control the opening and the closing of the Mosfet with a switching frequency $62.5 \mathrm{Khz}$.

In order to create an embedded system, a location is designed for the input/output of the Arduino board to mount it under our electronic card.

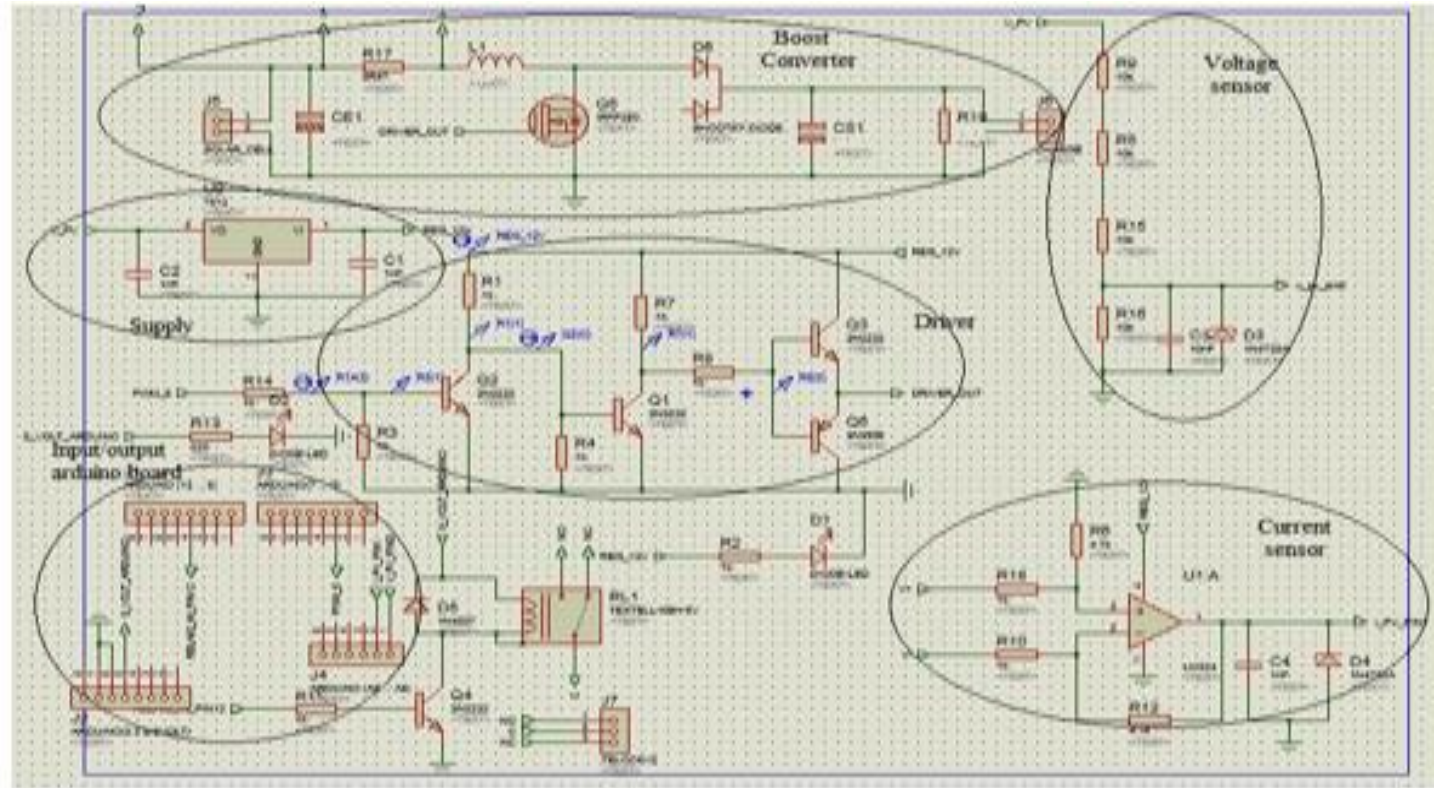

Figure 22. Design of whole system

\subsection{Hardware application}

As told before, the Arduino board is mounted under the designed converter as shown in Figure 23. The fabricated converter along with voltage and current sensors are shown in Figure 24. A support with variable size location is designed in order to control any PV panel. It's equipped with a light source imitating solar energy as shown in Figure 25 which indicate also MPPT's implementation that is used as battery charger.
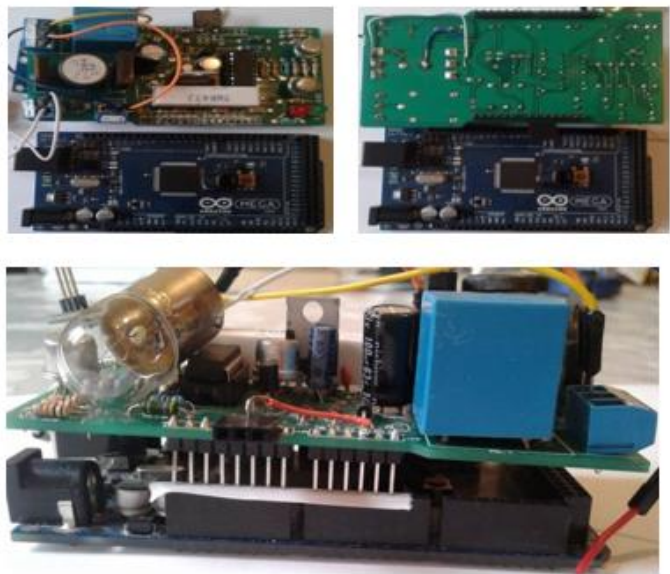

Figure 23. Location of the Arduino board

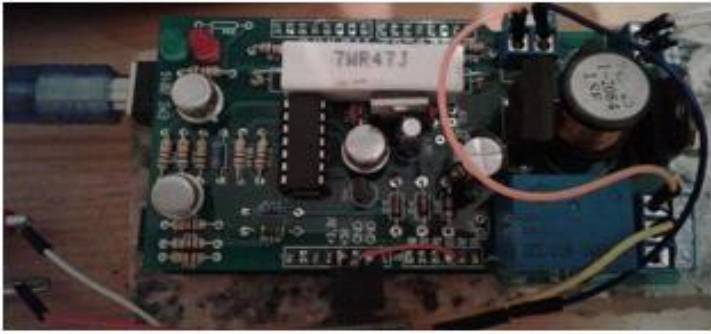

Figure 24. Designed boost converter 


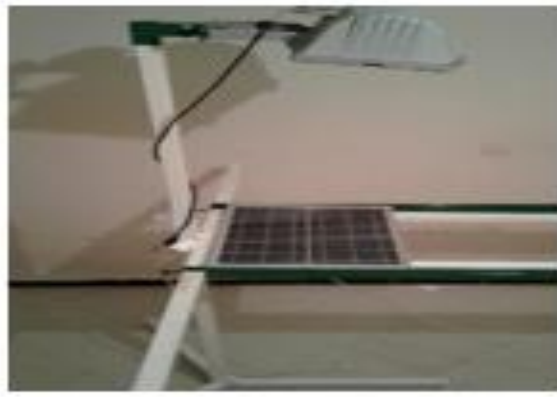

Figure 25. Support PV \& experimental system

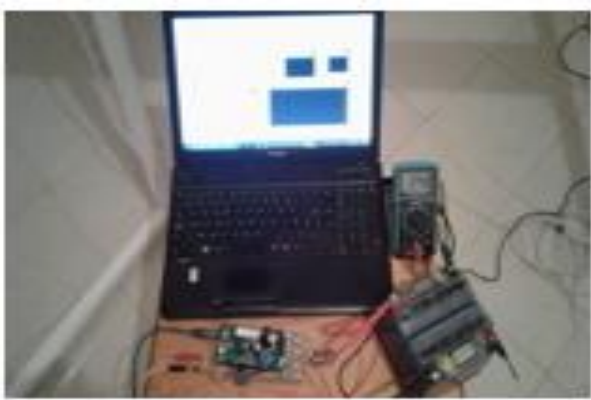

Figure 26 shows the input voltage of the driver with different value of duty cycle

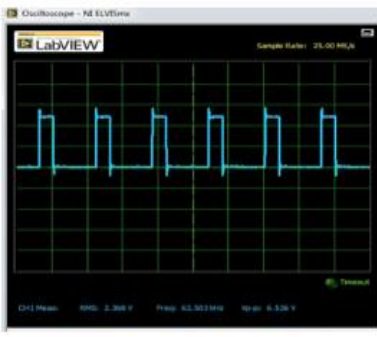

(a)

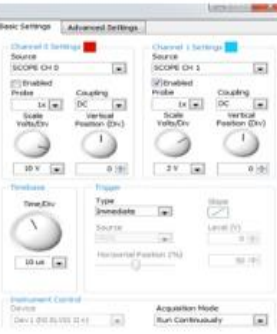

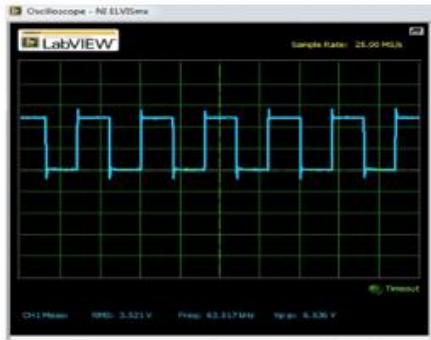

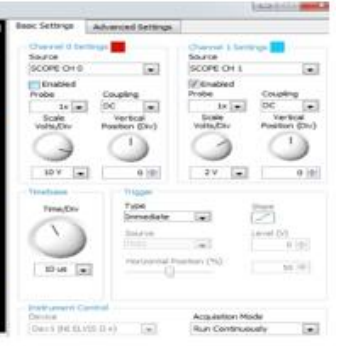

(b)
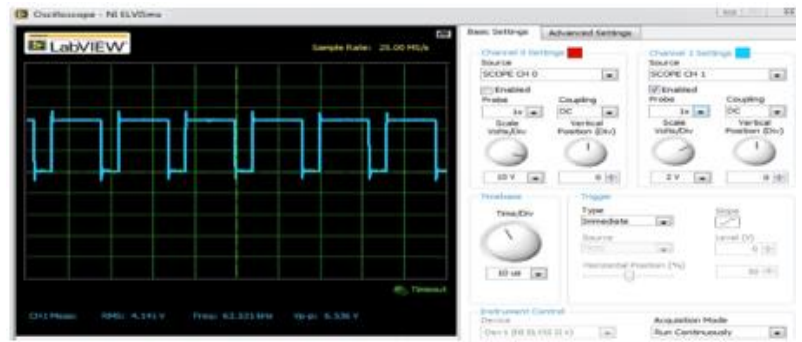

(c)

Figure 26. Input \& output of the driver, (a) $25 \%$ of duty cycle, (b) $50 \%$ of duty cycle, (c) $75 \%$ of duty cycle

\subsection{Software application}

In order to control and visualize the performance and the evolution of our system in real-time, a serial communication with a computer containing a graphical user interface is developed by exploiting Labview software [25].

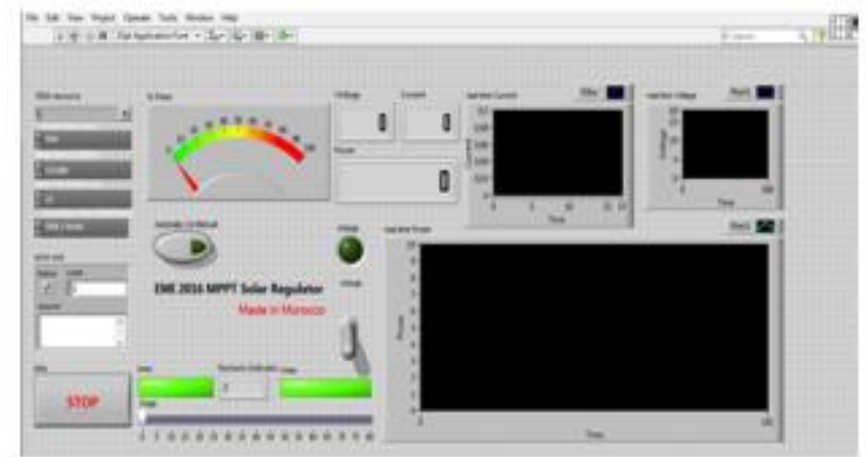

Figure 27. Graphical interface 

below:

The interface gives flexibility for users to control the system throughout diverse indicators listed

- $\quad$ A switch indictor defines which mode is used: manual or automatic.

- A measurements indicator allowing information to be viewed at real-time (current, voltage, power signals and values).

A performance indicator is displayed as a scale to show the efficiency.

To test our system and verify its performances, an incandescent lamp $(24 \mathrm{~V}, 5 \mathrm{~W})$ is used as a charge. $20 \mathrm{Watt}$ is the maximum power can generate from conversion of sun energy to electrical energy by PV.

Figure 28(a) shows that in the first $3 \mathrm{~s}$ the power value is closing to 5 Watt (4.126watt). The MPPT algorithm trying to find the maximum point, the PV panel voltage is decrementing from $17.47 \mathrm{~V}$ to 14.45 at $\mathrm{t}=4 \mathrm{~s}$, and the new power output obtained 4.377 Watt (Figure 28(b)), is compared with the previous value and the algorithm is repeated in order to achieve the MPP and deliver the power needed for the charge.

From Figure 28(c), we note that the value of the duty cycle is about 0.44 at $t=5 \mathrm{~s}$ which present a good concordance with value obtained by theoretical calculation, and the value of the power is almost 5 watt (4.97 watt) which means that the system presents very high efficiency.

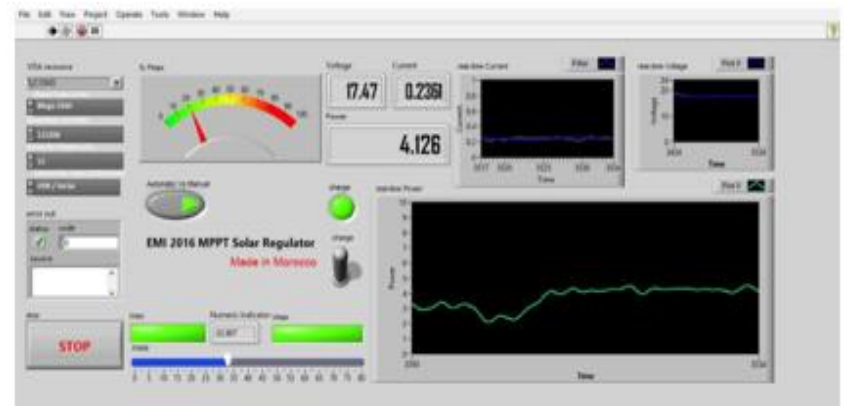

(a)

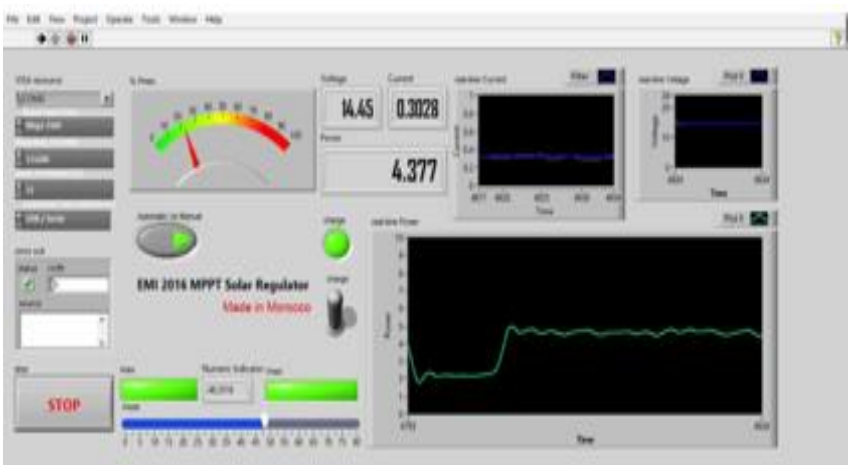

(b)

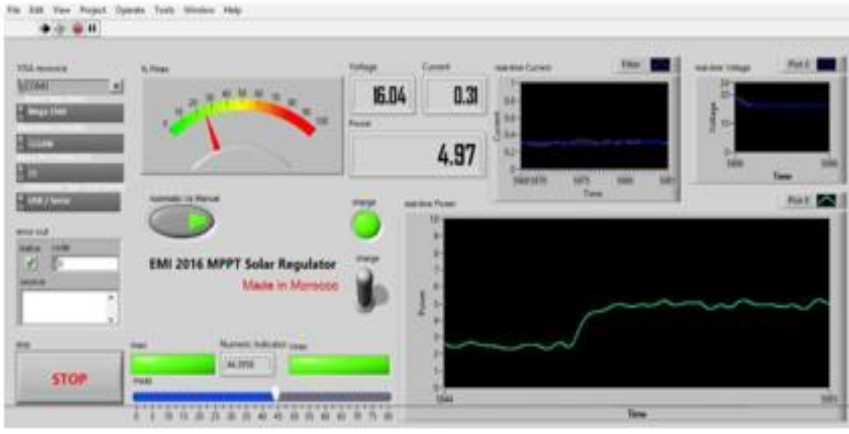

(c)

Figure 28. Labview user interface 


\section{CONCLUSION}

In this paper, a low-cost PV system has been designed and supervised in real time. It consists of a power and control card where the proposed ADRC MPPT strategy has been implemented to achieve the MPP even with climatic change. In the first part, The PV system has been performed using Pspice environment and Matlab Simulink to validate the developed model. In the second part, a test bench has been realized using a PV panel, Boost converter, driver, voltage and current sensors and an Arduino board. Finally, a graphical user interface built in Labview is used to offer a various ability which show that the proposed system gives very satisfactory results with a very good efficiency. The author strongly believes that this work is expected to provide more ideas for the researchers to apply the ADRC in a real prototype for power electronic converters control. The study indicates a promising prospect of ADRC in the future industry.

\section{REFERENCES}

[1] International Energy Agency, "Renewables 2019," IEA, Paris, 2019

[2] K. Kaliappan, M. Sankar, B. Karthikeyan, B. Vineeth, V.C. Raju, "Analysis of solar energy technology in leading countries," International Journal of Power Electronics and Drive System (IJPEDS), Vol. 10, No. 4, pp. 1995-2004, 2019, DOI: 10.11591/ijpeds.v10.i4.pp1995-2004.

[3] N. Femia, et al., "Predictive \& adaptive MPPT perturb and observe method," IEEE Transactions on Aerospace and Electronic Systems, vol. 43, no. 3, pp.934-950, 2007, DOI: 10.1109/TAES.2007.4383584.

[4] Lotfi Farah, Adel Haddouche, Ali Haddouche, "Comparison between proposed fuzzy logic and ANFIS for MPPT control for photovoltaic system," International Journal of Power Electronics and Drive Systems (IJPEDS), Vol. 11, No. 2, pp. 1065-1073, 2020, DOI: 10.11591/ijpeds.v11.i2.pp1065-1073.

[5] N. Khaldi, H. Mahmoudi, M. Zazi, and Y. Barradi "Modelling and Analysis of Neural Network and Incremental Conductance MPPT Algorithm for PV Array Using Boost Converter" In: Proc. of the 3rd International Conference on Energy and Environment Technologies and Equipment (EEETE '14), Brasov, Romania, June 26-28, 2014, pp 148-153.

[6] N. Khaldi, H. Mahmoudi, M, Zazi, Y, Barradi, "Implementation of a MPPT neural controller for photovoltaic systems on FPGA circuit," WSEAS Trans. on Power Systems, Vol. 9, pp 471-478, 2014.

[7] Turki Kahawish Hassan, "Reduction of single DC bus capacitance in photovoltaic cascaded multilevel converter," International Journal of Power Electronics and Drive System (IJPEDS), Vol.11, No.3, September 2020, pp. 16601674, DOI: 10.11591/ijpeds.v11.i3.pp1660-1674.

[8] H. Wang, X. Jin, H. Zhao, Y. Yue, "MPPT Control Method of PV System Based on Active disturbance rejection Control," IEEE, In Proc. of International Conference on Mechatronics and Automation, Takamatsu, Japan, 2017, pp. 337-341.

[9] O. A. Ahmed and J.A.M. Bleijs, "PSPICE and Simulink co-simulation for high efficiency DC-DC con-verter using SLPS interface software," 5th IET International Conference on Power Electronics, Machines and Drives, 2010.

[10] Y. Barradi, K. Zazi, M. Zazi, N. Khaldi, "A Novel Robust ADRCControl Strategy of a PMSG Based Wind Energy Conversion System" In: Proc. of the International Conference on Computer Science and Renewable Energies (ICCSRE), Agadir, Morocco, 22-24 July 2019, pp 1-6.

[11] Mohamed Amine Abdourraziq and Mohamed Maaroufi, "Experimental Verification of the Main MPPT Techniques for Photovoltaic System," International Journal of Power Electronics and Drive Systems (IJPEDS), pp. 384-391, 2017, DOI: 10.11591/ijpeds.v8.i1.pp384-391.

[12] Y. Barradi, K. Zazi, M. Zazi, N. Khaldi "Control of PMSG based variable speed wind energy conversion system connected to the grid with PI and ADRC approach," International Journal of Power Electronics and Drive System (IJPEDS), vol. 11, No. 2, pp 953-968, 2020, DOI: 10.11591/ijpeds.v11.i2.pp953-968.

[13] Y. Barradi, N. Khaldi, K. Zazi, M, Zazi," Comparative Analysis of Backstepping and Active Disturbance Rejection Control Approach used in Photovoltaic System Connected to the Grid," International Journal of Renewable Energy research (IJRER), vol. 9, No. 3, pp 1471-1479, 2019.

[14] N. Khaldi, H. Mahmoudi, M. Zazi, Y. Barradi, "The MPPT Control of PV System by Using Neural Networks Based on Newton Raphson Method," IEEE, the 2nd International Renewable and Sustainable Energy Conference (IRSEC'14) Ouarzazate, Morocco, pp. 1-6, October 17-19, 2014.

[15] Carlos Andr es Ramos-Paja, Daniel Gonz alez-Motoya, Juan Pablo Villegas-Ceballos, Sergio Ignacio SernaGarc'es, Roberto Gira "Sliding-mode controller for a photovoltaic system based ona'Cuk converter," International Journal of Electrical and Computer Engineering (IJECE), vol. 11, No. 3, pp 2027-2044, 2021, DOI: 10.11591/ijece.v11i3.pp2027-2044.

[16] A. A. Siddik and M. Shangeetha, "Implementation of Fuzzy Logic Controller in photovoltaic Power generation using Boost converter and Boost Inverter," International Journal of Power Electronics and Drive System (IJPEDS), vol. 2, no. 3, pp. 249-256, 2012, DOI: 10.11591/ijpeds.v2i3.334.

[17] S. Narendiran, Sarat Kumar Sahoo, Raja Das, "Control and Analysis of MPPT Techniques for Maximizing Power Extraction and Eliminating Oscillations in PV System," International Energy Journal, vol. 16, pp. 107-118, 2016.

[18] I. Houssamo, F. Locment, M. Sechilariu, "Experimental analysis of impact of MPPT methods on energy efficiency for photovoltaic power systems," International Journal of Electrical Power \& Energy Systems, Vol. 46, pp 98-107, 2013. 
[19] L. Sun, J. Dong, D. Li, and K. Y. Lee, "A practical multivariable control approach based on inverted decoupling and decentralized active disturbance rejection control," Industrial \& Engineering Chemistry Research, Vol. 55, pp 2008-2019, 2016, DOI: 10.1021/acs.iecr.5b03738.

[20] S. Yi Huang, W. Zhang, "Development of active disturbance rejection controller," Control Theory \& Applications, Vol. 19, pp 485-492, 2005.

[21] C. Z. El Archi, T. Nasser, and A. Essadki, "Power Control of DFIG Based Wind System: Comparison BetweeN Active Disturbance Rejection Controller and PI Controller," ARPN Journal of Engineering and Applied Sciences, vol. 11, No. 23, pp.13980-13989, 2016.

[22] G. Herbst, "A Simulative Study on Active Disturbance Rejection Control (ADRC) as a Control Tool for Practitioners," Electronics, pp. 246-279, 2013, DOI: 10.3390/electronics2030246.

[23] Z. Gao, 'Scaling and Bandwidth-Parameterization based Controller Tuning" In Proc. of the American Control Conference, Denver, CO, United States, Vol. 6, 2003, pp. 4989-4996.

[24] L. Li, Y. Chen, H. Zhou, H. Ma, J. Liu, "The application of hall sensors ACS712 in the protection circuit of controller for humanoid robots," IEEE, In Proc. of International Conference on Computer Application and System Modelling (ICCASM '10), Taiyuan, China, October 22-24, 2010.

[25] Y. Yadav, R. Roshan, S. Umashankar, D. Vijayakumar, D. P. Kothari "Real time simulation of solar photovoltaic module using Labview data acquisition card," In: Proc. of the International Conference on Energy Efficient Technologies for Sustainability, Nagercoil, India, April 10-12, 2014, pp 512-523.

\section{BIOGRAPHIES OF AUTHORS}
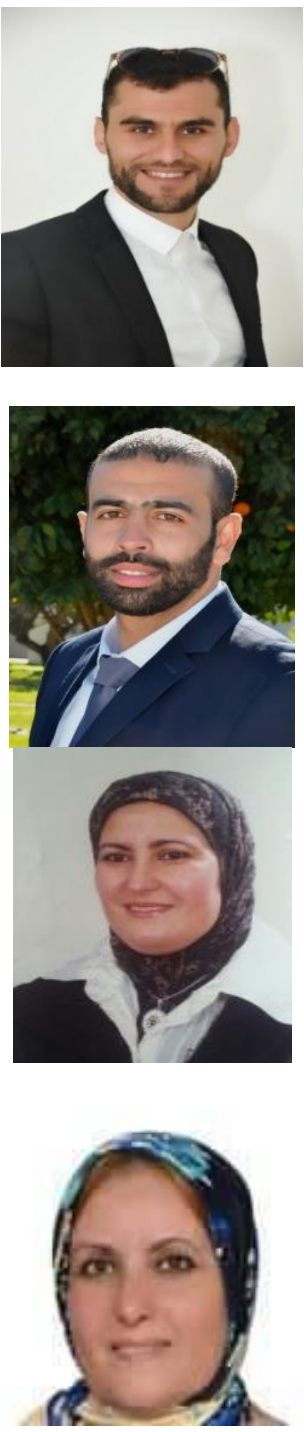

Khaldi Naoufel was born in Rabat, Morocco. He received his PhD degree in electrical engineering from University Mohammed V in 2019. His research interests include solar energy conversion, neural network and robust backstepping for control, simulation and supervision in real time. Having worked as a professor at Moroccan Science school of engineering Casa for 4 years. Presently, he is professor at High School of Technology, Ibn Zohr University, Guelmim, Morocco since 2019.

Barradi Youssef was born in Kenitra, Morocco. He ireceived PhD degree in electrical engineering from University Mohammed V in 2021. His research interests include Solar and Wind Energy Conversion System, hybrid system, Backstepping and ADRC control, genetic algorithm and grid optimisation. he is the WINNER in INPEX 2017 USA for his Innovative autonomous honey extraction system, and winner of the DANISH grand prize in the category for demonstrating excellence in all categories: innovation, impact for development, desirability, feasibility, pitch and gender perspective. (INNOVATION LAB 2019).

Zazi Khalida received the degree of engineer in electromechanical in 1988 fromRabat Higher School of Mines (ESMR), and preparatory certificate of research in 1997 from School Mohammedia of Engineering and a doctoral thesis in photovoltaics in 2017 from Faculty of Science and Technology Mohanmmadia, University Hassan II Casablanca. Having worked as a researcher at the National Center for Scientific and Technical Research of Rabat (CNRST) in different laboratories: laboratory of scientific instrumentation and the laboratory of geophysics and in the unit of technologies and economy of renewable energies. Currently she is a teacher at the higher normal school of Technical Education of Rabat (ENSET)University Mohammed V Rabat since 2014.

Zazi Malika received the degree of engineer in automatics and industrial informatics in 1984 from School Mohammedia of Engineering, and the Ph.D. degree in electrical engineering in 2006 from Mohammadia School of engineering, University Mohammedia V Rabat. She has specialized in the linear and nonlinear control systems. Presently, she is serving as is director of pedagogical affairs and head of Electro Technical Robotic and Automatic Research Team ERERA. She has over 30years of teaching experience. She is guiding some doctorate students in Renewable Energy, Diagnostic, Robust Control and Electrical Engineering. 